\title{
PRAME as diagnostic marker and as regulator for cell fate decisions in germ cell cancers
}

\author{
Nina Neuhaus ${ }^{*} 1$ \\ ${ }^{1}$ Centre of Reproductive Medicine and Andrology (CeRA), University Hospital of Muenster, Germany
}

The study by Nettersheim et al (2016a) is a highly interesting work, revealing the potential of PRAME (preferentially expressed antigen of melanoma) for diagnostic discrimination of human type II germ cell cancers. Moreover, the presented data is incorporated into a model placing PRAME into a decisive position for the cell fate choice with regard to pluripotency or differentiation in primordial germ cells and seminomas.

Cancer/testis antigens (CTAs) have a specific expression profile as they can only be detected in human malignancies but not in healthy human tissues, with the exception of the testis. Based on this profile, CTAs are assumed to be involved in regulation of gene expression or cell cycle in tumour cells. In 1997 the CTA termed PRAME was first described (Ikeda et al, 1997). Because of its expression pattern, numerous studies focused on the potential of PRAME as a biomarker for monitoring minimal residual disease, for diagnosis of malignant diseases and even as candidate for immunotherapy (Ercolak et al, 2015, Field et al, 2016). Although expression of PRAME in healthy human testicular tissues has been shown (Ikeda et al, 1997), Nettersheim et al (2016a) are now the first to provide information on the expression profile in human primordial germ cells and in testicular germ cell cancers. Primordial germ cells are the precursors of the germline stem cells that provide the basis for lifelong spermatogenesis. Importance of the regulatory mechanisms guiding this differentiation is highlighted by the fact that developmentally arrested primordial germ cells are considered to be the origin of type II germ cell cancers. More specifically, these defect primordial germ cells are thought to transform into a precursor lesion, namely germ cell neoplasia in situ (GCNIS). Later in life, these cells give rise to seminomas or embryonal carcinomas, the latter of which can differentiate into teratomas, yolk-sac tumours and chorioncarcinomas (Oosterhuis and Looijenga, 2005). Although seminomas and embryonal carcinomas share expression of pluripotency markers, these testicular germ cell cancers show distinct expression patterns of SOX2 and SOX17, which are restricted to embryonal carcinomas and seminomas, respectively (de Jong et al, 2008).

Aiming to identify other key players accompanying the transition from a seminoma to an embryonal carcinoma,
Nettersheim et al (2015) recently established xenografting of seminoma cells into the flank of mouse hosts. This microenvironment resulted in cellular transition into an embryonal carcinomalike status. Intriguingly, the transition process was accompanied by an induction of SOX2 but down-regulation of SOX17 and interestingly, also PRAME.

This study follows up on PRAME expression characteristics. In particular, Nettersheim et al (2016a) performed a meta-analysis of RNA-sequencing data from rarely available human primordial germ cells (Guo et al, 2015, Irie et al, 2015, Tang et al, 2015) as well as analyses of testicular germ cell tissues and cell lines. Employing this elegant approach, PRAME expression was revealed in human primordial germ cells, normal adult human testes in GCNIS seminomas, but not in embryonal carcinomas. This distinct expression profile on the one hand, again, supports the germ cell origin of seminomas, but also highlights the possibility to use PRAME in combination with the established markers SOX2 and SOX17 for diagnostic discrimination of seminomas and embryonal carcinomas (Nettersheim et al, 2016a).

This study also evaluated the regulatory mechanisms influencing PRAME expression and action, respectively. Nettersheim et al showed the expression of PRAME to be regulated by DNA methylation in type II germ cell cancers, which is in line with previous data from myeloid leukemia cells (Schenk et al, 2007). Also, Nettersheim et al addressed the hypothesis that knock-down of PRAME renders TCam-2 cells sensitive towards retinoic acidinduced differentiation. Although this effect has been demonstrated for human melanoma cells (Epping et al, 2005), knock-down of PRAME in seminoma cells did not result in a sensitisation of TCam2 cells towards a retinoic acid-induced differentiation process.

Nonetheless, PRAME knock-down in TCam-2 cells did result in down-regulation of pluripotency regulators and an up-regulation of genes including factors associated with endodermal, mesodermal as well as germ cell differentiation. Importantly, expression of SOX17 was not altered, indicating an upstream function of this transcription factor.

Although the exact mechanism of PRAME action remains to be resolved, Nettersheim et al propose a model for PRAME function

*Correspondence: Dr N Neuhaus, E-mail: nina.neuhaus@ukmuenster.de 
in seminoma cells that is based on recent insights gained from mouse studies demonstrating that interaction of Sox 2 and Oct $3 / 4$ leads to binding to canonical motifs associated with pluripotency, whereas interaction of Sox 17 and Oct3/4 leads to binding to compressed motifs associated with differentiation (Aksoy et al, 2013, Viotti et al, 2014). In the human, however, SOX17 expression in primordial germ cells and seminoma cells does not lead to spontaneous differentiation. Rather, SOX17 has recently been described as master regulator at the time of germ cell specification, leading to transactivation of primordial germ cell markers (Guo et al, 2015, Irie et al, 2015, Tang et al, 2015). Also, the ability of SOX17 to bind canonical motifs suggests that in seminomas, SOX2 may be replaced by SOX17 in the pluripotency cluster. Based on these recent findings and their own data, Nettersheim et al therefore propose that the presence of PRAME leads to binding of SOX17/OCT4 dimers to canonical motifs, leading to expression of pluripotency factors and manifestation of the primordial germ cell or seminoma cell identity. In the absence of PRAME, however, binding of SOX17/OCT4 dimers changes toward the compressed motifs, leading to expression of germ and somatic cell differentiation markers (Nettersheim et al 2016a).

In three very recent publications (Nettersheim et al, 2015, $2016 \mathrm{a}$, b) this group has unravelled molecular changes that accompany the transition from seminoma to embryonal carcinoma. They also propose intriguing models for the respective cellular mechanisms. The model concerning cellular mechanisms of PRAME presented in this study will need to be substantiated by further functional studies.

\section{CONFLICT OF INTEREST}

The author declares no conflict of interest.

\section{REFERENCES}

Aksoy I, Jauch R, Chen J, Dyla M, Divakar U, Bogu GK, Teo R, Leng Ng CK, Herath W, Lili S, Hutchins AP, Robson P, Kolatkar PR, Stanton LW (2013) Oct4 switches partnering from Sox2 to Sox17 to reinterpret the enhancer code and specify endoderm. EMBO J 32: 938-953.

de Jong J, Stoop H, Gillis AJ, van Gurp RJ, van de Geijn GJ, Boer M, Hersmus R, Saunders PT, Anderson RA, Oosterhuis JW, Looijenga LH (2008) Differential expression of SOX17 and SOX2 in germ cells and stem cells has biological and clinical implications. J Pathol 215: 21-30.
Epping MT, Wang L, Edel MJ, Carlee L, Hernandez M, Bernards R (2005) The human tumor antigen PRAME is a dominant repressor of retinoic acid receptor signaling. Cell 122: 835-847.

Ercolak V, Paydas S, Bagir E, Ergin M, Seydaoglu G, Celik H, Yavu B, Tanriverdi K, Gunaldi M, Afsar CU, Duman BB (2015) PRAME expression and its clinical relevance in Hodgkin's lymphoma. Acta Haematol 134: 199-207.

Field MG, Decatur CL, Kurtenbach S, Gezgin G, van der Velden PA, Jager MJ, Kozak KN, Harbour JW (2016) PRAME as an Independent biomarker for metastasis in uveal melanoma. Clin Cancer Res 22: 1234-1242.

Guo F, Yan L, Guo H, Li L, Hu B, Zhao Y, Yong J, Hu Y, Wang X, Wei Y, Wang W, Li R, Yan J, Zhi X, Zhang Y, Jin H, Zhang W, Hou Y, Zhu P, Li J, Zhang L, Liu S, Ren Y, Zhu X, Wen L, Gao YQ, Tang F, Qiao J (2015) The transcriptome and DNA methylome landscapes of human primordial germ cells. Cell 161: 1437-1452.

Ikeda H, Lethe B, Lehmann F, van Baren N, Baurain JF, de Smet C, Chambost H, Vitale M, Moretta A, Boon T, Coulie PG (1997) Characterization of an antigen that is recognized on a melanoma showing partial HLA loss by CTL expressing an NK inhibitory receptor. Immunity 6: 199-208.

Irie N, Weinberger L, Tang WW, Kobayashi T, Viukov S, Manor YS, Dietmann S, Hanna JH, Surani MA (2015) SOX17 is a critical specifier of human primordial germ cell fate. Cell 160: 253-268.

Nettersheim D, Arndt I, Sharma R, Riesenberg S, Jostes S, Schneider S, Hölzel M, Kristiansen G, Schorle H (2016a) The cancer/testis-antigen PRAME supports the pluripotency network and represses somatic and germ cell differentiation programs in seminomas. BJC; e-pub ahead of print 21 July 2016; doi:10.1038/bjc.2016.187.

Nettersheim D, Heimsoeth A, Jostes S, Schneider S, Fellermeyer M, Hofmann A, Schorle H (2016b) SOX2 is essential for in vivo reprogramming of seminoma-like TCam-2 cells to an embryonal carcinoma-like fate. Oncotarget; e-pub ahead of print 7 June 2016; doi:10.18632/oncotarget.9903.

Nettersheim D, Jostes S, Sharma R, Schneider S, Hofmann A, Ferreira HJ, Hoffmann P, Kristiansen G, Esteller MB, Schorle H (2015) BMP inhibition in seminomas initiates acquisition of pluripotency via NODAL signaling resulting in reprogramming to an embryonal carcinoma. PLoS Genet 11: e1005415.

Oosterhuis JW, Looijenga LH (2005) Testicular germ-cell tumours in a broader perspective. Nat Rev Cancer 5: 210-222.

Schenk T, Stengel S, Goellner S, Steinbach D, Saluz HP (2007) Hypomethylation of PRAME is responsible for its aberrant overexpression in human malignancies. Genes Chromosomes Cancer 46: 796-804.

Tang WW, Dietmann S, Irie N, Leitch HG, Floros VI, Bradshaw CR, Hackett JA, Chinnery PF, Surani MA (2015) A unique gene regulatory network resets the human germline epigenome for development. Cell 161: 1453-1467.

Viotti M, Nowotschin S, Hadjantonakis AK (2014) SOX17 links gut endoderm morphogenesis and germ layer segregation. Nat Cell Biol 16: $1146-1156$. 